\title{
Streptococcus pneumoniae Acquisition and Carriage
}

\author{
Chand Wattal $^{1}$ - J. K. Oberoi ${ }^{1}$
}

Received: 21 August 2019 / Accepted: 23 August 2019 / Published online: 13 September 2019

(C) Dr. K C Chaudhuri Foundation 2019

It is well accepted that invasive pneumococcal disease is a major cause of morbidity and mortality among children $<2$ $\mathrm{y}$ and adults $>65 \mathrm{y}$ of age. This gets further worse in some comorbid conditions like HIV disease and hematological malignancies of all age groups [1]. In children, pneumococcal conjugate vaccine (PCV) has significantly controlled the impact of the invasive pneumococcal disease (IPD) [2]. India accounted for around 68,700 pneumococcal deaths in children in 2015 [3]. High nasopharyngeal colonization has been found in several studies in India [3]. The most common ten serotypes found in a study from South India were 1, 3, 5, 19F, 8, 14, 23F, 4,19 and $6 \mathrm{~B}$ and accounted for $54.9 \%$ of IPD cases. In this study, penicillin non-susceptibility was $6.4 \%$ higher than earlier report of $3 \%$ [1]. International guidelines recommend pneumococcal conjugated vaccine (PCV) in all high risk groups like HIV, as reviewed by Lopez et al. [4].

Nasopharyngeal carriage in toddlers and infants is a potential source for horizontal transmission in the community [5]. The serotypes (ST) circulating across the country do vary geographically; thirty five (77.7\%) STs isolated from south were PPCV 7 and 13 vaccine types. In vaccinated and non-vaccinated children it is important to know the colonizing ST for predictability of vaccine (PCV) efficacy in a community. All isolates were vancomycin sensitive and susceptible to levofloxacin. However, penicillin resistance varied between 3-6\%. In pneumococcal meningitis group, $27.4 \%$ and $9.9 \%$ isolates were nonsusceptible to penicillin and cefotaxime, respectively $[1,6]$. As per the study published here in this issue of IJP by Arya et al. [7], in children and parents with HIV, it was found that colonization in children and their parents with HIV was $31 \%$ and in those without HIV was $32 \%$, indicating not much difference and the common vaccine types were $6 \mathrm{~A}, 6 \mathrm{~B}$ and $19 \mathrm{~A}$ [7].

Chand Wattal

chandwattal@gmail.com

1 Clinical Microbiology \& Immunology, Sir Ganga Ram Hospital, Rajinder Nagar, New Delhi, India
In a study of 245 HIV/AIDS patients, nasopharyngeal swabs revealed $11 \%(95 \% \mathrm{CI} ; 7.4$ to 15.6$)$ carriage among children and $25 \%$ (95\% CI:14\% to $38.9 \%$ ) carriage among adults [8]. Among 200 healthy children aged between 3 mo and 3 y attending Pediatric OPD at Sir Ganga Ram Hospital, the pneumococcal carriage rate was found to be $6.5 \%$. Isolates belonged to serotypes 1, 6, 14 and 19, of which serotype 19 was the most common [9]. In a prospective 2-year pneumococcal surveillance study in patients with communityacquired pneumococcal infections of $\geq 50$ years' age group, the most common serotypes observed in the study were 19A $(14 \%), 8(10 \%), 19 \mathrm{~F}(8 \%), 3(6 \%)$ and $9 \mathrm{~N}(6 \%)$. The nonvaccine serotypes $(\mathrm{NVTs})$ comprised $30 \%(\mathrm{n}=15)$ of the isolates [10]. IPD was significantly associated with pneumococcal carriage. As per this study the most prevalent pneumococcal serotypes were 19A and 23F. It was found that pneumococcal carriage among HIV infected children was 3-fold higher compared to the carriage among HIV infected adults and predominates with non-vaccine ST [8].

The burden of pneumococcal disease is further complicated by the increasing resistance in HIV infected individuals, may be due to the routine prophylactic use of co-trimoxazole [8]. PCV 10 introduction in Kenya decreased the carriage rate of pneumococci in children as well as adults with HIV [11]. However, in post PCV 10 vaccinated children, the colonization of multi-drug resistant (MDR) pneumococcus including penicillin intermediate susceptible pneumococcus non vaccine types emerged in children. Similar findings were reported both in U.S. children and adults post PCV 7 introduction [11].

India introduced PCV 13 in 6 states in 2017-19 (Himachal Pradesh, Rajasthan, Bihar, Uttar Pradesh, Madhya Pradesh and Haryana). Children with IPD and the ones with only carriage were studied (91 IPD and 510 community children). The proportion colonized with S. pneumoniae (SP) was $74.7 \%$ and $54.5 \%$ among children with IPD and community children, respectively. The PPCV-13 ST was similar in both groups and the most common STs were $6 \mathrm{~A}, 6 \mathrm{~B}, 14,19 \mathrm{~A}, 19 \mathrm{~F}$ and $23 \mathrm{~F}$ and all were represented in PCV-13. Drug resistance was more common in IPD types (25.8\% vs. 16.4\%) [3]. 


\section{Compliance with Ethical Standards}

Conflict of Interest None.

\section{References}

1. Jayaraman R, Varghese R, Kumar JL, et al. Invasive pneumococcal disease in Indian adults: 11 years' experience. J Microbiol Immunol Infect. 2018. https://doi.org/10.1016/j.jmii.2018.03.004 .

2. Moore MR, Link-Gelles R, Schaffner W, et al. Effect of use of 13valent pneumococcal conjugate vaccine in children on invasive pneumococcal disease in children and adults in the USA: analysis of multisite, population-based surveillance. Lancet Infect Dis. 2015;15:301-9.

3. Sutcliffe CG, Shet A, Varghese R, et al. Nasopharyngeal carriage of Streptococcus pneumoniae serotypes among children in India prior to the introduction of pneumococcal conjugate vaccines: a crosssectional study. BMC Infect Dis. 2019;19:605.

4. Lopez A, Mariette X, Bachelez A, et al. Vaccination recommendations for the adult immunosuppressed patient: a systematic review and comprehensive field synopsis. J Autoimmun. 2017;80:10-27.

5. van Aalst M, Lotsch F, Spijker R, et al. Incidence of invasive pneumococcal disease in immunocompromised patients: a systematic review and meta-analysis. Travel Med Infect Dis. 2018;24:89-100.
6. Thomas K, Kesavan LM, Veeraraghavan B, et al. Invasive pneumococcal disease associated with high case fatality in India. J Clin Epidemiol. 2013;66:36-43.

7. Arya BK, Bhattacharya SD, Harigovind G, et al. Streptococcus pneumoniae acquisition and carriage in vaccine naïve Indian children with HIV and their parents: a longitudinal household study. Indian J Pediatr. 2019. https://doi.org/10.1007/s12098-019-02995-4.

8. Dayie NT, Baffuor-Asare M, Labi AK, et al. Epidemiology of pneumococcal carriage among HIV-infected individuals in the conjugate vaccine era: a study in Southern Ghana. Biomed Res Int. 2019;2019:3427174. https://doi.org/10.1155/2019/3427174 eCollection 2019.

9. Wattal C, Oberoi JK, Pruthi PK, Gupta S. Nasopharyngeal carriage of Streptococcus pneumoniae. Indian J Pediatr. 2007;74:905-7.

10. Wattal C, Goel N, Byotra SP. Prevalence of pneumococcal serotypes in adults $\geq 50$ years of age. Indian J Med Microbiol. 2017;35: 95-100.

11. Kobayashi M, Bigogo G, Kim L, et al. Impact of 10-valent pneumococcal conjugate vaccine introduction on pneumococcal carriage and antibiotic susceptibility patterns among children aged $<5$ years and adults with HIV infection, Kenya 2009-2013. Clin Infect Dis. 2019 Apr 9. pii: ciz285. https://doi.org/10.1093/cid/ciz285. [Epub ahead of print]

Publisher's Note Springer Nature remains neutral with regard to jurisdictional claims in published maps and institutional affiliations. 